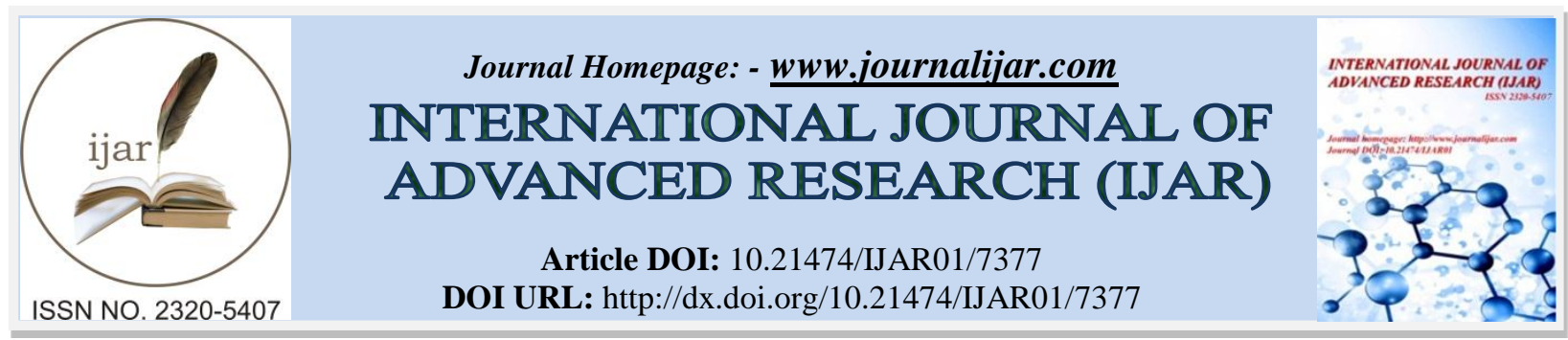

RESEARCH ARTICLE

\title{
PAEDIATRIC ORAL HEALTH - PERCEPTIONS OF PAEDIATRICIANS IN URBAN VIJAYAWADA, INDIA.
}

\section{KTSS. Rajajee ${ }^{1}$, Chaitanya Ram Kandregula ${ }^{2}$, Ravichandra KS $^{3}$, Apoorva Gaddapati ${ }^{4}$, Disha Lakhotia ${ }^{5}$ and} Kandarpa Balakrishna ${ }^{6}$.

1. Head of the department, Department of Pedodontics, Anil neerukonda institute of dental sciences, Visakhapatnam.

2. Reader, Department of Pedodontics, Anil neerukonda institute of dental sciences, Visakhapatnam.

3. Head of the Department, Department of Pedodontics,Drs.S\&N R SIDS, Vijayawada.

4. Pediatric dentist, Visakhapatnam.

5. Pediatric dentist, Vijayawada.

6. Professor, Department of Pedodontics, Anil neerukonda institute of dental sciences, Visakhapatnam.

\section{Manuscript Info}

Manuscript History

Received: 09 May 2018

Final Accepted: 11 June 2018

Published: July 2018

Keywords:-

Paediatricians, knowledge, attitude, practice, first dental visit, dental caries.

\section{Abstract}

Aim: Children visit the Paediatricians more often than a dentist and thus it is crucial that they be aware of the dental diseases and their consequences in children. This will enable them to make an early diagnosis and appropriate referral to a pediatric dentist. Hence the present study was undertaken to assess the knowledge, attitude and practice of currently practicing Paediatricians on oral health care of children from urban Vijayawada.

Methodology: A structured questionnaire survey made up of 20 items pertaining to knowledge on oral health, attitude and practice towards dentistry was distributed among 57 Paediatricians and given scores based on 3 point Likert scale. The collected data was tabulated using Microsoft excel for any predictable patterns. The results were analyzed taking absolute percentages of the responses into consideration.

Results: Of the 57 eligible participants, 51 responded out of which 50 duly completed the questionnaire. Of the eligible respondents, only $18 \%$ believed that dental caries is a transmissible disease and $54 \%$ considered to avoid medicated sugary syrups as they cause early dental caries. Most of them accepted the need for an interdisciplinary approach between Paediatrician and Paediatric dentist to offer better oral health for differently abled children.

Conclusion: This study shows that most of the paediatricians from urban Vijayawada have appropriate knowledge, attitude and practice towards dentistry especially paediatric dentistry. However, few misconceptions regarding paediatric dentistry need to be addressed.

Copy Right, IJAR, 2018,. All rights reserved.

\section{Introduction:-}

Emphasis on prevention of dental diseases rather than cure among children has been quintessential focus of Pedodontics. However, majority of children in India are not ensured of proper dental care, leave alone preventive 
practices and this can be attributed to minimal awareness and misconceptions about paediatric dental care amongst our society. ${ }^{1}$

Although the professional bodies of Paediatric Dentistry insist on the child to have first dental visit by the time the first tooth erupts into the oral cavity and to have regular visits thereafter, the reality is far different in developing countries like India especially for children in low socio economic strata. ${ }^{2}$ The medical office can be considered an opportune site to reach large number of children as they pay regular visits to a medical office but not dental unless it's really in need. The medical professionals, Paediatricians and their auxiliaries in particular need to have some basic knowledge about dental disease patterns, positive attitude towards dentistry and dental specialists and the motivation to do the needful for the patients. To put this into practice, they need to be harnessed in identifying the dental problems, counsel their parents regarding prevention and send appropriate referral to a dentist. Though knowledgeable, at times they inadvertently disregard the dental findings. Lack of motivation, not realizing the importance of good oral hygiene, sparse availability of paediatric dentists and interdisciplinary communication disparity may be attributed to the above.

As Paediatricians are the ones who have preliminary access to children and it is imperative that they need to have apposite awareness towards oral health care. Hence, the present study was undertaken to evaluate the knowledge, attitude and practices of paediatricians on oral health care of children from urban Vijayawada.

\section{Methodology:- \\ Settings:-}

A cross-sectional, self-administered, structured questionnaire survey in English was conducted to assess the knowledge, attitude and practices of paediatricians on oral health care of children from urban Vijayawada.

\section{Participants:-}

The present survey was conducted among Paediatricians of Vijayawada city, Andhra Pradesh registered under the IMA (Indian Medical Association). A total of 71 Paediatricians were registered under IMA, Vijayawada of which 57 are practicing in Vijayawada. All the 57 of them were included in the study. The study group comprised of specialists from various backgrounds confined to paediatric practice only. Paediatric specialists not practicing were excluded from the study.

\section{Questionnaire:-}

Data was collected through a structured questionnaire made up of 20 items pertaining to knowledge on oral health, attitude and practice towards dentistry as well as dentists especially paediatric dentists. The questionnaire was delivered personally to the respondents. All the participants were asked to answer each question, anything between Agree, Disagree and Do not know.

\section{Scoring Criteria:-}

The questionnaire consisted of a total of 20 randomly distributed questions on knowledge, attitude and practice which are based on 3 point Likert scale (Agree, Disagree and Do not know). Only duly filled questionnaires were considered and the incomplete ones were invalidated.

The collected data was tabulated using Microsoft excel for any predictable patterns. The results were analyzed taking absolute percentages of the responses into consideration.

\section{Results and discussion:-}

Of the 57 questionnaires distributed, 51 were returned out of which 50 duly completed only were accepted for the study and the one incomplete was invalidated. Also, the participants included both genders $(24 \%$ females and $76 \%$ males) with ages ranging from 33 to 63 years. The collected data was tabulated using Microsoft Excel and reorganized, sub grouping it under the knowledge, attitude and practice categories.

Several studies since the mid -1970s point to a direct association between oral S.mutans levels in children and their primary caregivers, suggesting that managing adult reservoirs may interfere with transmission that holds strong promise in reducing dental caries onset and experience. ${ }^{4-6}$ In the present survey, majority of paediatricians $(78 \%)$ opined that dental caries is not a transmissible disease which is in accordance with some former studies ${ }^{7}$ but not 
with others. ${ }^{89}$ Geographic variations can be attributed to this divergence in opinions. This suggests that information about dental disease patterns to paediatricians in this area is the need of the hour.

On the contrary, most of the participants (86\%) seem to be aware of the role sugar plays in aggravating caries and this corresponds to some earlier studies. ${ }^{8}$ It is surprising to know that $88 \%$ of the study group believed that fluoride supplements and sealants have a role in prevention of dental caries. Some studies concur with our study ${ }^{2,7}$ but for one that claims paediatricians prefer normal dentifrice than a fluoridated one. ${ }^{10}$

The understanding among the paediatricians in our study about nocturnal feeding practices as a cause for early dental decay is more (88\%) when compared to a study by Kumari et al $(63.5 \%)^{2}$ but almost similar to the findings reported by Bhat et al (91.6\%). ${ }^{9}$ Majority of the respondents $(92 \%)$ agreed that systemic diseases influence the oral health of an individual.

Majority of the study sample agreed that deleterious habits like thumb sucking can cause irregularities of the teeth/jaws (92\%) and potential irregularities of the teeth/jaws can be averted by early referral of children to dentists. (94\%) Therefore, discussions on non-nutritive sucking with the parents and caregivers should be initiated by the paediatricians and dentists as early as 6-12 months addressing the benefits of the habit as well as the potential changes to the oral structures that negate the advantages if the habit becomes too intense. ${ }^{11}$

All the paediatricians are unanimous in being aware about practicing general and specialist dentists around their area. Also, most of the participants realized the importance of primary teeth which was in conformation with some of the former studies. ${ }^{3,12}$ However, majority of the participants $(70 \%)$ have expressed their unwillingness in actually demonstrating oral hygiene measures. These findings suggest that the paediatricians actually must be motivated to involve themselves in demonstration of oral hygiene measures so as to harness the full potential of paediatricians in promoting oral health.

Eighty two percent of this study group have recognized the role of dentist in managing cleft lip and palate and $94 \%$ have firmly believed in inter disciplinary approach for attaining better oral health in a differently abled child. These figures are higher when compared to a prior study that reported $64 \%$ of paediatricians accepting dentists role in managing cleft lip and palate and only $47 \%$ believed in inter disciplinary approach. ${ }^{3}$ The role of dentist in managing differently abled children must be plainly explained to the medical fraternity so as to enable team approach and circumvent any fallacies.

The concept of oral cavity emulating systemic health is shared by $78 \%$ of the Paediatricians while $12 \%$ disagreed. Many of the systemic disorders reflect in the oral cavity and few of them have a direct bearing on the dental health. ${ }^{13,14}$ At times the dental disease may be the primary aetiology for a systemic disease. However, most of the medical practitioners take no notice of dental findings and this suggests that when evaluating systemic health, the medical practitioners have to be encouraged to pay attention to any significant dental findings as well. This can happen only when the medical professional has essential knowledge about dental diseases and their implications. It is also useful if the medical workforce has some basic information about the role of preventive dentistry to eradicate dental diseases. Steps to educate medical practitioner in this direction may result in early referrals from medical personnel to dentists so as to undertake any preventive measures.

All participants in the study preferred referring children to a paediatric dentist than general dentist. Most of the prior studies laid less emphasis on paediatricians actually involving in counselling children about oral hygiene practices. ${ }^{2,3,7}$ All participants in this study group believed in emphasizing counselling about oral hygiene practices which is a heartening trend. However, $70 \%$ of paediatricians are not directly willing to involve themselves that needs to be addressed.

Sixty six percent of paediatricians agreed that the right age to start oral health examination is soon after birth which is in correspondence with one previous study where in which 59.3\% of paediatricians opined that the first dental visit be before the eruption of teeth. ${ }^{8}$ On the contrary, most of the respondents in other studies suggested dental visits between one and three years of age. ${ }^{15-17}$ The current trend of visiting a dentist soon after birth is adopted based on extensive research suggesting a correlation between dental caries and microbiological components even before the teeth erupt into oral cavity. ${ }^{4-6,18}$ Contemporary preventive methods to anticipate and combat dental diseases are 
designed taking the above into consideration and after thorough understanding about dental disease patterns. Medical professionals need to be educated and stressed upon the importance of early dental visits.

Almost half of the participants linked medicated sugary syrups with cariogenicity which is higher than a previous study where in which only $27 \%$ felt the same. ${ }^{3}$ However, Subramaniam et al, in their study reported that majority of paediatricians $(90.2 \%)$ have associated medicated sugary syrups with dental caries. ${ }^{10}$ Evidence in the literature substantiates the cariogenic potential of medicated sugary syrups and dentists are well aware of this phenomenon. ${ }^{19-}$

${ }^{20}$ Unfortunately, most of the medical professionals are less attentive to the repercussions of medicated syrups because their prime focus is on delivering the medicine and ignore the consequences of syrups on dental health. Medical professionals need to be informed of the consequences of medicated sugary syrups and appealed to substitute the former with non-sugary syrups, if possible.

This study shows that most of the paediatricians from urban Vijayawada have appropriate knowledge, attitude and practice towards dentistry especially paediatric, contrary to those reported in some other studies. ${ }^{3,8,21}$ However, as the case with most questionnaire surveys, the answers might have been influenced by the social and ethical responsibility of the paediatricians therefore may not be reflecting their original practices and attitude. The drawbacks of the study include that, the questionnaires were not involving any details regarding the years and type of practice (group /solo or government/private) which may have affected the outcome of the survey. Also, the closed ended nature of the questionnaire might have influenced the outcome of the study. Further studies encompassing the above variables should be undertaken in this area so as to eliminate any untoward biases limiting paediatricians from expressing themselves.

The negative biases, misconceptions and lack of interest by some of the participants highlight educating and motivating medical professionals towards better dental health is the need of the hour. Publishing articles on oral health for medical professionals in medical periodicals and journals can help in improve the knowledge, attitudes and practices of medical professional towards dentistry there by mitigating the above mentioned barriers. The importance of dental education for a medical professional must be emphasized from the undergraduate medical curriculum. Also, steps should be taken to overcome the communication gap between the dental and medical health professionals through inter professional meets bringing medical and dental professionals on the same platform. This can help improve inter professional relations there by eliminating any misconceptions and create a positive attitude towards dentistry. This may benefit the dental profession / society indirectly as the medical profession has far and wider reach and can exert greater influence.

\section{Conclusion:-}

The present study is first of a kind in this area and divulged some of the trends pertaining to paediatricians towards dentistry especially paediatric dentistry. Most of the paediatricians are affirmative towards paediatric dentistry and seems to be aware about the importance of primary teeth, deleterious oral habits, sugars, fluorides, inter-disciplinary approach in managing differently-abled child, early dental visits \& intervention. Surprisingly, majority think that caries is non-transmissible and the opinion is mixed when it comes to medicated sugary syrups. However, the study did not take into consideration the years and type of practice. Further studies taking the above variables into consideration may depict the precise picture pertaining to the local trends. Though, the paediatricians realize the importance of paediatric oral health, their apathy towards participation in preventive measures reveal the urgency that they must be educated and motivated to take the lead role in promoting paediatric oral health.

\section{What is already known?}

Paediatricians and dental professionals play an inter-disciplinary role in promoting child's overall health.

\section{What this study adds?}

Data of this study shows that although knowledgeable, paediatricians continue to have certain misconceptions regarding oral health in children. 


\section{References:-}

1. Pinkham J, Casamassimo P, Fields H, McTigue, Nowak A, 4th ed. Pediatric dentistry Infancy through adolescence, Elsevier Inc; 2005.

2. Kumari NR, Sheela S, Sarada PN. Knowledge and attitude on infant oral health among graduating medical students in Kerala. J Indian Soc Pedod Prev Dent 2006;24(4): 173-6.

3. Nammalwar RB, Rangeet P. Knowledge and attitude of paediatricians and Family Physicians in Chennai on pediatric dentistry: A survey. Dent Res J 2012; 9: 561-6.

4. Douglass JM, Li Y, Tinanoff N. Association of mutans streptococci between caregivers and their children. Pediatr Dent 2008; 30(5): 375-87

5. Berkowitz RJ and Jones P. Mouth to mouth transmission of the bacterium Streptococcus mutans between mother and child. Arch Oral Biol 1985; 30: 377-9

6. Caufield PW, Ratanapridakul K, Allen DN, Cutter GR. Plasmid containing strains of Streptococcus mutans cluster within family and racial cohorts: Implication in natural transmission. Infect Immun 1988; 56: 3216-20.

7. Murthy GA, Mohandas U. The knowledge, attitude and practice in prevention of dental caries amongst paediatricians in Bangalore: a cross sectional study. J Indian Soc Pedod Prev Dent. 2010; 28 (2): 100-3.

8. Balaban R, Aguiar CM, da Silva Araujo AC, Dias Filho EB. Knowledge of paediatricians regarding child oral health. Int J Pediatr Dent 2012; 22(4): 286-91.

9. Padma K. Bhat, Aruna C.N., Bhumika K. Badiyani, Rajkumar Alle. Knowledge and Attitude on Infant Oral Health among graduating Medical Students in Bangalore City, India. JIMSA 2014; 27(1): 13 -14

10. Subramaniam P, Babu KL, Babu PS, Naidu P. Oral health care in children: Gynecologists and Pediatricians prespective. J Clin Pediatr Dent 2008; 32(3): 253-8.

11. Berg J.H and Slayton R.L. Early childhood oral health. Wiley- Blackwell, 2009

12. Prakash P, Lwarence HP, Harvey BJ, McIssac WJ, Limeback H, Leak JL. Early childhood caries and infant oral health: paediatricians and family physicians knowledge, practices and training. Paediatr Child Health 2006; 11: $151-7$

13. Meyle, J. and Gonzáles, J. R. (2001), Influences of systemic diseases on periodontitis in children and adolescents. Periodontology 2000, 26: 92-112.

14. Strauss S.M, Alfano M.C, Shelley D, and Fulmer T. Identifying Unaddressed Systemic Health Conditions at Dental Visits: Patients Who Visited Dental Practices but Not General Health Care Providers in 2008. Am J Public Health. 2012;102(2):253-5

15. Sezer RG, Paketci C, Bozaykut A. Paediatricians' awareness of children's oral health: Knowledge, training, attitudes and practices among Turkish paediatricians. Paediatr Child Health. 2013 ;18 (4):15-9.

16. Lewis CW, Boulter S, Keels MA, et al. Oral health and pediatrician: Results of a national survey. Acad Pediatr. 2009;9: 457-61.

17. Caspary G, Krol DM, Boulter S, Keels MA, Romano-Clarke G. Perceptions of oral health training and attitudes toward performing oral health screenings among graduating pediatric residents. Pediatrics.2008;122: 465-71.

18. American Academy of Pediatric Dentistry. Policy on the dental home. Reference manual 2014; 36: 24-25

19. Tupalli AR, Satish B, Shetty BR, Battu S, Kumar JP, Nagaraju B. Evaluation of the Erosive Potential of Various Pediatric Liquid Medicaments: An in-vitro Study. J Int Oral Health. 2014 Feb; 6(1): 59-65.

20. Babu KLG, Doddamani GM, Naik LRK, Jagadeesh KN. Pediatric liquid medicaments - Are they cariogenic? An in vitro study. J Int Soc Prev Community Dent. 2014; 4(2): 108-112.

21. Feigal RJ, Donly KJ. The use of pit and fissure sealants. Pediatr Dent 2006; 28 : 143-50 